\title{
Lesions of the commissural subnucleus of the nucleus of the solitary tract increase isoproterenol-induced water intake
}

\author{
G.T. Blanch ${ }^{1}$, \\ A.H. Freiria-Oliveira ${ }^{1}$, \\ E. Colombari ${ }^{1,2}$, J.V. Menani ${ }^{1}$ \\ and D.S.A. Colombari ${ }^{1}$
}

\author{
${ }^{1}$ Departamento de Fisiologia e Patologia, Faculdade de Odontologia, \\ Universidade Estadual Paulista, Araraquara, SP, Brasil \\ ${ }^{2}$ Departamento de Fisiologia, Escola Paulista de Medicina, \\ Universidade Federal de São Paulo, São Paulo, SP, Brasil
}

\author{
Correspondence \\ D.S.A. Colombari \\ Departamento de Fisiologia e \\ Patologia \\ Faculdade de Odontologia, UNESP \\ Rua Humaitá, 1680 \\ 14801-903 Araraquara, SP \\ Brasil \\ FAX: +55-16-3301-6488 \\ E-mail: deborac@foar.unesp.br \\ Part of a thesis presented by \\ G.T. Blanch to the Federal \\ University of São Carlos, São \\ Carlos, SP, Brasil, in partial \\ fulfillment of the requirements \\ for the Doctoral degree. \\ Research supported by FAPESP \\ (Nos. 03/05275-6 and 03/08768-3). \\ $\ldots \ldots \ldots \ldots \ldots \ldots$
}

Received August 10, 2006

Accepted May 14, 2007

\section{Abstract}

The nucleus of the solitary tract (NTS) is the primary site of the cardiovascular afferent information about arterial blood pressure and volume. The NTS projects to areas in the central nervous system involved in cardiovascular regulation and hydroelectrolyte balance, such as the anteroventral third ventricle region and the lateral parabrachial nucleus. The aim of the present study was to investigate the effects of electrolytic lesion of the commissural NTS on water and 0.3 $\mathrm{M} \mathrm{NaCl}$ intake and the cardiovascular responses to subcutaneous injection of isoproterenol. Male Holtzman rats weighing 280 to $320 \mathrm{~g}$ were submitted to sham lesion or electrolytic lesion of the commissural NTS (N = 6-15/group). The sham-lesioned rats had the electrode placed along the same coordinates, except that no current was passed. Water intake induced by subcutaneous isoproterenol $(30 \mu \mathrm{g} / \mathrm{kg}$ body weight) significantly increased in chronic (15 days) commissural NTS-lesioned rats (to $2.4 \pm 0.2 \mathrm{vs}$ sham: $1.9 \pm 0.2 \mathrm{~mL} 100 \mathrm{~g}$ body weight ${ }^{-1} 60 \mathrm{~min}^{-1}$ ). Isoproterenol did not induce any sodium intake in sham or in commissural NTS-lesioned rats. The isoproterenol-induced hypotension (sham: $-27 \pm 4$ vs commissural NTS-lesioned rats: $-22 \pm 4 \mathrm{mmHg} / 20 \mathrm{~min}$ ) and tachycardia (sham: $168 \pm 10 \mathrm{vs}$ commissural NTS: $144 \pm 24 \mathrm{bpm} / 20 \mathrm{~min}$ ) were not different between groups. The present results suggest that the commissural NTS is part of an inhibitory neural pathway involved in the control of water intake induced by subcutaneous isoproterenol, and that the overdrinking observed in lesioned rats is not the result of a cardiovascular imbalance in these animals.

\section{Introduction}

Several studies have demonstrated that the hindbrain is involved in the inhibitory control of water intake and salt appetite, in contrast to forebrain areas, that mainly exert
Key words

- Nucleus of the solitary tract

- Commissural nucleus of the rat solitary tract

- Water intake

- Arterial pressure

- Isoproterenol

- Hindbrain
.....................

an excitatory drive on water and sodium intake (1-6).

Electrolytic or ibotenic acid lesions of the lateral parabrachial nucleus (LPBN) located in the pons increase water intake induced by subcutaneous $(s c)$ injections of 
angiotensin II (ANG II) or isoproterenol $(3,7)$, a $B$-adrenergic agonist that induces thirst by activating the renin-angiotensin system and decreasing blood pressure $(8,9)$. The blockade of the serotonergic mechanisms of the LPBN with methysergide, a serotonergic 5-HT1/5-HT2 receptor antagonist, also increases central ANG II-induced water intake and sodium appetite induced by fluid depletion and central ANG II and drives rats to ingest hypertonic $\mathrm{NaCl}$ after subcutaneous isoproterenol $(5,10,11)$. Animals with lesions of the area postrema (AP), another hindbrain area, also display a high daily consumption of hypertonic $\mathrm{NaCl}$ solution and increased water intake in response to subcutaneous ANG II or isoproterenol $(1,12)$.

The nucleus of the solitary tract (NTS), located in the dorsal medulla, is the primary site of cardiovascular afferents in the central nervous system (13). The medial NTS (mNTS) and the commissural NTS (commNTS) subnuclei project to the forebrain areas involved in the control of hydroelectrolyte balance, such as the paraventricular nucleus and the anteroventral third ventricle region and to hindbrain areas such as the LPBN (14-16) and receive projections from the AP (17). Besides playing a well-established role in cardiovascular regulation (18-20), the NTS may also be involved in the control of fluid balance. Lesions of the mNTS increase the ingestion of water in response to intravenous ANG II and this effect has been attributed to the impairment of the baroreflex or to a loss of an inhibitory signal produced by water consumption (21).

Although different studies have suggested that signals that reach the NTS from peripheral arterial and cardiopulmonary baroreceptors are important for the control of water and sodium intake (22-25), no study has investigated the possible role of commNTS on ANG II-mediated water intake. In addition, a previous study (11) showed that treatment with isoproterenol drives rats to ingest hypertonic $\mathrm{NaCl}$ after the blockade of LPBN- inhibitory mechanisms. Therefore, the aim of the present study was to investigate the effects of electrolytic lesion of the commNTS on water and $0.3 \mathrm{M} \mathrm{NaCl}$ intake after subcutaneous injection of isoproterenol, a drug that activates the renin-angiotensin system (9). Since isoproterenol induces hypotension, and this can facilitate water and sodium intake $(22,26)$, we also evaluated the effects of isoproterenol on blood pressure in commNTS-lesioned rats.

\section{Material and Methods}

\section{Animals}

Male Holtzman rats weighing 280 to 320 $\mathrm{g}$ were used. The animals were housed individually in stainless steel cages in a room with controlled temperature $\left(23 \pm 2^{\circ} \mathrm{C}\right)$ and humidity $(55 \pm 10 \%)$. Lights were on from 7:00 am to 7:00 pm. Standard Purina chow and tap water were available ad libitum. The Ethics Committee for Animal Care and Use of the Dental School of Araraquara, UNESP, approved the experimental protocols used in the present study.

\section{Commissural NTS lesions}

Rats were anesthetized with intraperitoneal ketamine (Francotar, Virbac, Jurubatuba, SP, Brazil, $80 \mathrm{mg} / \mathrm{kg}$ body weight) combined with xylazine (Xilazin, Syntec, Cotia, SP, Brazil, $7 \mathrm{mg} / \mathrm{kg}$ body weight) and adapted to a stereotaxic apparatus (model 900, David Kopf Instruments, Tujunga, CA, USA). A partial craniotomy of the occipital bone was performed, and the dorsal surface of the brain stem was exposed. A tungsten electrode $(0.1 \mathrm{~mm}$ in diameter) was inserted into the brain using the following coordinates: $0.4,0.7$, and $1.0 \mathrm{~mm}$ caudal to the calamus scriptorius, on the midline and 0.2 $\mathrm{mm}$ below the dorsal surface of the brain stem. The electrolytic lesion was performed using a cathodal current ( $1 \mathrm{~mA}$ for $5 \mathrm{~s})$. A 
clip attached to the tail was used as the indifferent electrode. The sham-lesioned rats had the electrode placed along the same coordinates, but no current was passed. A prophylactic dose of penicillin $(30,000 \mathrm{IU})$ was given intramuscularly after surgery to all rats.

\section{Water and $0.3 \mathrm{M} \mathrm{NaCl}$ intake tests}

Water and $0.3 \mathrm{M} \mathrm{NaCl}$ intake was measured in a group of rats with chronic (15 days) commNTS $(\mathrm{N}=10-14)$ or sham $(\mathrm{N}=8-15)$ lesions using glass burettes with $0.1-\mathrm{mL}$ divisions fitted with a metal drinking spout. Cumulative water and $0.3 \mathrm{M} \mathrm{NaCl}$ intake was measured at 30, 60, 90, and $120 \mathrm{~min}$ starting immediately after sc isoproterenol (30 $\mu \mathrm{g} / \mathrm{kg}$ body weight) or saline injection. Water and $0.3 \mathrm{M} \mathrm{NaCl}$ intake is reported as $\mathrm{mL} / 100 \mathrm{~g}$ body weight.

\section{Arterial pressure and heart rate recording}

Another group of rats with chronic (15 to 18 days $)$ commNTS $(\mathrm{N}=10)$ or sham $(\mathrm{N}=$ 6) lesion was prepared to record mean arterial pressure (MAP) and heart rate (HR). On the day before the experiment, under anesthesia with intraperitoneal ketamine $(80 \mathrm{mg} /$ $\mathrm{kg}$ body weight) combined with xylazine (7 $\mathrm{mg} / \mathrm{kg}$ body weight), polyethylene tubing (PE-10 connected to a PE-50) was inserted into the abdominal aorta through the femoral artery. Arterial and venous catheters were tunneled subcutaneously and exposed on the back of the rat to allow access in unrestrained, freely moving rats. To record pulsatile arterial pressure, MAP and HR in conscious animals, the arterial catheter was connected to a Statham Gould (P23 Db) (El Segundo, CA, USA) pressure transducer coupled to a pre-amplifier (model ETH-200 Bridge Bio Amplifier, Chicago, IL, USA) that was connected to a Powerlab computer data acquisition system (model Powerlab 16SP, ADInstruments, Colorado Springs,
CO, USA). Twenty minutes after starting the cardiovascular recordings, rats received an $s c$ injection of isoproterenol $(30 \mu \mathrm{g} / \mathrm{kg}$ body weight), and the recordings were performed for an additional $90 \mathrm{~min}$.

\section{Histology}

At the end of the tests, the animals were anesthetized deeply with sodium thiopental ( $80 \mathrm{mg} / \mathrm{kg}$ body weight) and perfused transcardially with saline followed by $10 \%$ formalin. The brains were removed, fixed in $10 \%$ formalin, frozen, cut into $50-\mathrm{mm}$ sections, stained with Giemsa, and analyzed by light microscopy to confirm the commNTS lesions.

\section{Statistical analysis}

Data are reported as means \pm SEM. Twoway analysis of variance (ANOVA) followed by the Student-Newman-Keuls test or nonpaired $t$-test were used for comparisons. Differences were considered significant at $\mathrm{P}<$ 0.05 .

\section{Results}

\section{Histological analysis}

Figure 1 shows the typical commNTS lesion in a rat representative of the animals tested. Lesions of the commNTS were located in the midline above the central canal and extended $\sim 1 \mathrm{~mm}$ caudally from the level

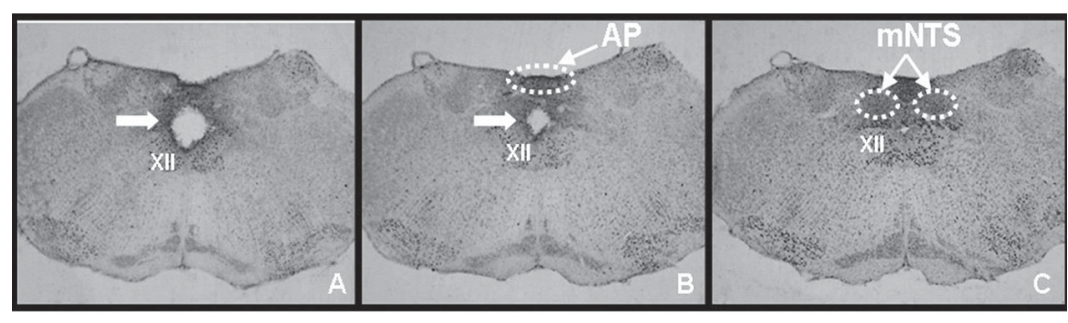

Figure 1. Photomicrographs of sequential coronal caudo-rostral sections (A to $\mathrm{C}$ ) of the nucleus of the solitary tract (NTS) showing a representative lesion of the commissural NTS ( $\mathrm{A}$ and $\mathrm{B}$, arrows). $\mathrm{AP}=$ area postrema; $\mathrm{XII}=$ hypoglossal nucleus; $\mathrm{mNTS}=$ medial $\mathrm{NTS}$ (Giemsa stain; 12.5X). 
of the calamus scriptorius. Lesions were restricted to the commNTS, leaving intact the mNTS, hypoglossus nucleus (XII), and the AP. The size and the position of the lesions were similar to those in our earlier studies $(27,28)$.

Table 1. Pre-lesion body weight and body weight 2 and 15 days after sham or commissural nucleus of the solitary tract (commNTS) lesions.

\begin{tabular}{ccc}
\hline & \multicolumn{2}{c}{ Group } \\
\cline { 2 - 3 } & Sham $(\mathrm{N}=23)$ & commNTS $(\mathrm{N}=24)$ \\
\hline Pre-lesion & $303 \pm 2$ & $308 \pm 3$ \\
2 days & $310 \pm 3$ & $288 \pm 3^{*+}$ \\
15 days & $355 \pm 4^{*}$ & $334 \pm 6^{*+}$ \\
\hline
\end{tabular}

Data are reported as means \pm SEM. $N=$ number of rats.

${ }^{*} \mathrm{P}<0.05$ compared to pre-lesion values; ${ }^{+} \mathrm{P}<$ 0.05 compared to sham animals (two-way ANOVA, followed by the Student-Newman-Keuls test)

Figure 2. $A$, Cumulative water intake; $B$, cumulative $0.3 \mathrm{M} \mathrm{NaCl}$ intake ( $\mathrm{mL} / 100 \mathrm{~g}$ body weight) by sham and commissural nucleus of the solitary tract (commNTS)-lesioned rats (15 days) treated with $s c$ isoproterenol $(30$ $\mu \mathrm{g} / \mathrm{kg}$ body weight) or saline $(0.15 \mathrm{M} \mathrm{NaCl})$. Data are reported as means \pm SEM. $\mathrm{N}=$ number of rats. ${ }^{*} \mathrm{P}<0.05 \mathrm{com}$ pared to sc saline; ${ }^{+} \mathrm{P}<0.05$ compared to sham animals (twoway ANOVA, followed by the Student-Newman-Keuls test).
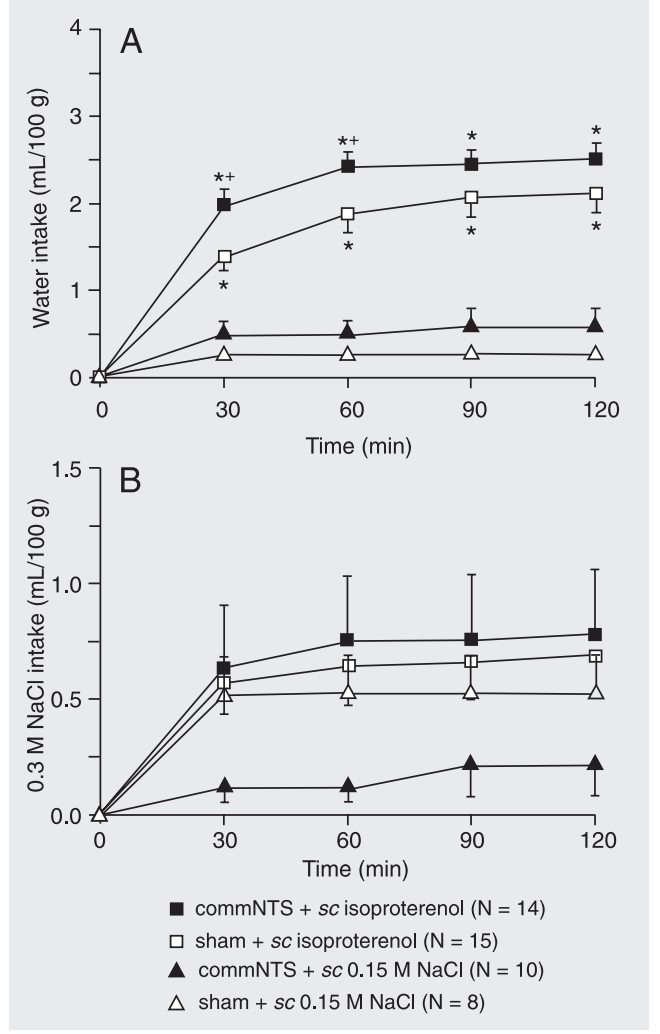

\section{Body weight}

As demonstrated in Table 1, pre-lesion weights did not differ between groups (commNTS: $308 \pm 3$ g vs sham: $303 \pm 2$ g). Two days after brain surgery the body weight of commNTS-lesioned rats was reduced (288 $\pm 3 \mathrm{~g}$ ), while the body weight of sham rats was similar $(310 \pm 3 \mathrm{~g})$ to pre-lesion values. On the day of the experiment, 15 days after the brain lesion, commNTS-lesioned rats and sham rats gained weight compared to their pre-lesion body weight. However, the body weight gain of commNTS-lesioned rats was lower than that of sham rats $(\mathrm{F}(1,132)=$ 14.69; $\mathrm{P}<0.05$; Table 1).

\section{Effects of commissural NTS lesion on water} and $0.3 \mathrm{M} \mathrm{NaCl}$ intake after subcutaneous isoproterenol injection

Animals with commNTS lesions ingested more water than sham rats after $s c$ isoproterenol during the first $60 \mathrm{~min}$ of testing $(2.4$ \pm 0.2 vs sham: $1.9 \pm 0.2 \mathrm{~mL} / 100 \mathrm{~g}$ body weight $\left.{ }^{-1} 60 \mathrm{~min}^{-1}\right)$. Both groups also ingested more water after $s c$ isoproterenol than after saline (sham: $0.3 \pm 0.04$ and commNTS: 0.6 $\pm 0.2 \mathrm{~mL} / 100 \mathrm{~g}$ body weight ${ }^{-1} 120 \mathrm{~min}^{-1}$; $\mathrm{F}(12,210)=2.53 ; \mathrm{P}<0.05 ;$ Figure 2A). There was no sodium intake in any group of rats after $s c$ isoproterenol (sham: $0.7 \pm 0.2$ vs commNTS: $0.7 \pm 0.3 \mathrm{~mL} / 100 \mathrm{~g}$ body weight $^{-1} 60 \mathrm{~min}^{-1}$ ) or sc saline (sham: $0.5 \pm$ 0.2 vs commNTS: $0.2 \pm 0.1 \mathrm{~mL} / 100 \mathrm{~g}$ body weight $^{-1} 60 \mathrm{~min}^{-1} ; \mathrm{F}(12,210)=0.25 ; \mathrm{P}=$ 0.996; Figure 2B).

Effects of commissural NTS lesion (15 to 18 days) on mean arterial pressure and heart rate after subcutaneous isoproterenol injection

Baseline MAP (sham: $118 \pm 6 v s$ commNTS: $118 \pm 5$ mmHg; P > 0.05; nonpaired $t$-test) and HR (sham: $370 \pm 12 \mathrm{vs}$ commNTS: $371 \pm 21$ bpm; $\mathrm{P}>0.05$; non- 
paired $t$-test) did not differ between groups. A comparable decrease in MAP was observed in sham and in commNTS-lesioned rats ( $\triangle$ MAP sham: $-27 \pm 4$ vs commNTS: -22 $\pm 4 \mathrm{mmHg} / 20 \mathrm{~min} ; \mathrm{F}(10,154)=0.19 ; \mathrm{P}=$ 0.997), as also observed for HR $(\Delta \mathrm{HR}$ sham: $168 \pm 10$ vs commNTS: $144 \pm 24 \mathrm{bpm} / 20$ $\min ; \mathrm{F}(10,154)=0.16 ; \mathrm{P}=0.999 ;$ Figure 3$)$.

\section{Specificity of commissural NTS lesions in producing the effects on water intake after subcutaneous isoproterenol}

To show the specificity of commNTS as the site where electrolytic lesions increase isoproterenol-induced water intake, the results from animals with lesions placed outside the commNTS (misplaced lesions) that received $s c$ isoproterenol $(\mathrm{N}=6)$ or $s c$ saline $(\mathrm{N}=7)$ were also analyzed. Misplaced lesions were either small lesions, or non-uniform lesions, or lesions positioned ventrally to the commNTS. Rats with misplaced commNTS lesions and sham rats treated with $s c$ isoproterenol ingested similar amounts of water (sham: $1.9 \pm 0.2 v s$ commNTS: 1.9 $\pm 0.3 \mathrm{~mL} / 100 \mathrm{~g}$ body weight $\left.{ }^{-1} 60 \mathrm{~min}^{-1}\right)$. Both groups ingested also more water after $s c$ isoproterenol than after saline (sham: 0.3 \pm 0.04 and commNTS: $0.3 \pm 0.1 \mathrm{~mL} / 100 \mathrm{~g}$ body weight $60 \mathrm{~min}^{-1} ; \mathrm{F}(12,170)=1.8 ; \mathrm{P}<$ $0.05)$. Treatment with isoproterenol induced no significant sodium intake in sham rats $(0.6 \pm 0.2 v s$ saline: $0.5 \pm 0.2 \mathrm{~mL} 100 \mathrm{~g}$ body weight $\left.{ }^{-1} 60 \mathrm{~min}^{-1}\right)$ or in rats with misplaced lesions $(0.9 \pm 0.3$ vs saline: $0.4 \pm 0.2 \mathrm{~mL} 100$ g body weight ${ }^{-1} 60 \mathrm{~min}^{-1} ; \mathrm{F}(12,170)=0.26$; $\mathrm{P}=0.994)$.

\section{Discussion}

The present results show a significant increase in isoproterenol-induced water intake in commNTS-lesioned rats. The role of the NTS, including the commNTS, in the control of the cardiovascular reflexes has been extensively studied (18-20,27). The new finding of the present study is that the commNTS also contributes to water intake control and may represent an essential step in the neural pathways involved in the regulation of water intake induced by $s c$ isoproterenol. However, commNTS lesions do not affect sodium intake in rats treated with $s c$ isoproterenol.

The overdrinking observed in commNTSlesioned rats after $s c$ isoproterenol was similar to that observed in studies using LPBN $(3,7)$ and AP (12) lesions. Considering the anatomical connections among these areas and the behavioral data, it seems that the commNTS is also part of the hindbrain inhibitory pathways involved in the control of water intake. Besides projecting to the LPBN, the commNTS also sends efferents to the forebrain $(14,15)$. Thus, it is possible that the commNTS exerts a direct inhibitory influence on forebrain mechanisms that regulate water intake, such as in the anteroventral third ventricle region, inhibiting the water intake signal independently of the LPBN.

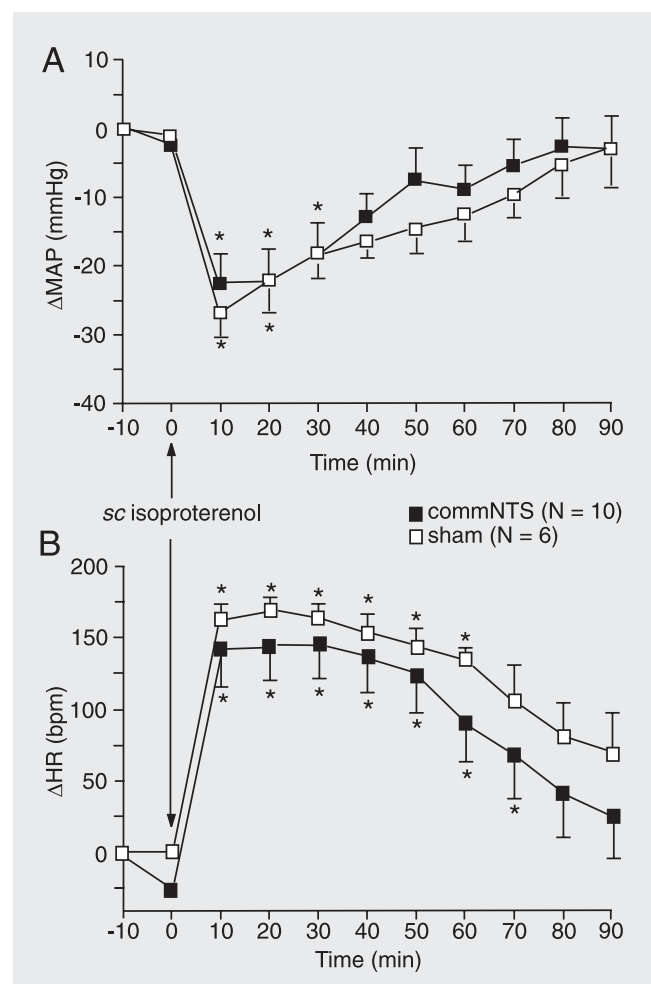

Figure 3. Changes in mean arterial pressure (MAP) (A) and heart rate $(H R)(B)$ induced by subcutaneous $(s c)$ isoproterenol (30 $\mu \mathrm{g} / \mathrm{kg}$ body weight) in sham and in commissural nucleus of the solitary tract (commNTS)-lesioned rats (15 to 18 days). Data are reported as means \pm SEM. $\mathrm{N}=$ number of rats. ${ }^{*} \mathrm{P}<0.05$ compared to time 0 (two-way ANOVA, followed by the Student-Newman-Keuls test). 
The increase in isoproterenol-induced water intake in animals with commNTS lesions may result from the increase in facilitatory signals or the blockade of inhibitory signals. Water intake induced by $s c$ isoproterenol depends on the activation of the renin-angiotensin system and on a decrease of blood pressure $(8,9)$. Hypotension is a mechanism that facilitates water intake (22) and a more intense hypotension in response to isoproterenol in commNTS-lesioned rats would be a reason for the increased water intake. However, the present results demonstrate that commNTS lesions do not affect isoproterenol-induced hypotension, which suggests that the increase in water intake is not related to changes in cardiovascular responses to $s c$ isoproterenol. Increases in plasma ANG II after sc isoproterenol in commNTS-lesioned rats also possibly explain the increase in water intake. Although we cannot exclude this possibility, it is necessary to consider that one important signal for the release of renin, i.e., hypotension, is not affected by commNTS lesion.

The activation of the cardiopulmonary receptors by atrial stretch inhibits water intake induced by isoproterenol and other dipsogenic challenges (25). Arterial baroreceptor activation also inhibits drinking induced by systemic ANG II (24). Signals from cardiopulmonary receptors and baroreceptors reach the NTS (13). Therefore, it is possible that commNTS lesions impair inhibitory signals from cardiopulmonary and arterial baroreceptors that are important to limit isoproterenol-induced water intake $(24,25)$. However, the NTS exerts a differential control on the cardiovascular reflexes. While mNTS lesions block the baroreflex (29), commNTS lesions do not change the baroreflex (27). Because of this, commNTS lesions more likely affect cardiopulmonary signals than baroreceptor signals. It is interesting to note that peripheral isoproterenol can also activate mechano- and chemosensitive receptors in the cardiac ventricles that send signals through afferent vagal $\mathrm{C}$ fibers (30). Therefore, besides the activation of facilitatory signals (ANG II), isoproterenol acting on cardiopulmonary receptors might also inhibit water intake, and this effect would be blocked by commNTS lesions.

Differently from other hindbrain areas like the LPBN and AP $(4,11,31)$, commNTS lesions surprisingly do not affect sodium intake. Isoproterenol injection does not induce sodium intake (32) despite the high levels of ANG II and the hypotension that have been implicated in mediating salt appetite $(6,26,33)$. However, in rats injected with methysergide into the LPBN, sc isoproterenol elicits ingestion of a significant amount of $0.3 \mathrm{M} \mathrm{NaCl}$, which suggests that any activation of sodium intake produced by isoproterenol is strongly inhibited by inhibitory mechanisms that have LPBN as a relay (11). Besides, AP/mNTS lesions increase daily ad libitum intake of hypertonic sodium solution (1) and enhance consumption of concentrated saline solution $(3 \% \mathrm{NaCl})$ during the first few hours after presentation of saline to sodium-repleted rats (31). Therefore, it is possible that projections from the $\mathrm{AP} / \mathrm{mNTS}$ to the LPBN are involved in the control of water and sodium intake $(1-5,7,10$ 12,31), while, as suggested by the present data, the commNTS is involved only in the control of water intake.

The present results suggest that the commNTS is part of an inhibitory neural pathway involved in the control of water intake induced by $s c$ isoproterenol, and that the overdrinking observed in commNTSlesioned rats is not the result of a cardiovascular imbalance in these animals.

\section{Acknowledgments}

The authors thank Reginaldo C. Queiroz, Silas P. Barbosa and Silvia Fóglia for expert technical assistance, Silvana A.D. Malavolta for secretarial assistance, and Ana L.V. de Oliveira for animal care. 


\section{References}

1. Contreras RJ, Stetson PW. Changes in salt intake after lesions of the area postrema and the nucleus of the solitary tract in rats. Brain Res 1981; 211: 355-366.

2. Hyde TM, Miselis RR. Area postrema and adjacent nucleus of the solitary tract in water and sodium balance. Am J Physiol 1984; 247 : R173-R182.

3. Ohman LE, Johnson AK. Lesions in lateral parabrachial nucleus enhance drinking to angiotensin II and isoproterenol. Am J Physiol 1986; 251: R504-R509.

4. Colombari DSA, Menani JV, Johnson AK. Forebrain angiotensin type 1 receptors and parabrachial serotonin in the control of $\mathrm{NaCl}$ and water intake. Am J Physiol 1996; 271: R1470-R1476.

5. Menani JV, Johnson AK. Lateral parabrachial serotonergic mechanisms: angiotensin-induced pressor and drinking responses. $A m \mathrm{~J}$ Physiol 1995; 269: R1044-R1049.

6. Johnson AK, Thunhorst RL. The neuroendocrinology of thirst and salt appetite: visceral sensory signals and mechanisms of central integration. Front Neuroendocrinol 1997; 18: 292-353.

7. Edwards GL, Johnson AK. Enhanced drinking after excitotoxic lesions of the parabrachial nucleus in the rat. Am J Physiol 1991; 261 : R1039-R1044.

8. Hosutt JA, Rowland N, Stricker EM. Hypotension and thirst in rats after isoproterenol treatment. Physiol Behav 1978; 21: 593-598.

9. Leenen $\mathrm{FH}, \mathrm{McD}$ onald $\mathrm{RH}$ Jr. Effect of isoproterenol on blood pressure, plasma renin activity, and water intake in rats. Eur J Pharmacol 1974; 26: 129-135.

10. Menani JV, Thunhorst RL, Johnson AK. Lateral parabrachial nucleus and serotonergic mechanisms in the control of salt appetite in rats. Am J Physiol 1996; 270: R162-R168.

11. Menani JV, De Luca L Jr, Thunhorst RL, Johnson AK. Hindbrain serotonin and the rapid induction of sodium appetite. Am J Physiol Regul Integr Comp Physiol 2000; 279: R126-R131.

12. Edwards GL, Ritter RC. Area postrema lesions increase drinking to angiotensin and extracellular dehydration. Physiol Behav 1982; 29 : 943-947.

13. Palkovits M, Zaborsky L. Neuroanatomy of central cardiovascular control. Nucleus tractus solitary: afferent and efferent neuronal connections in relation to baroreceptor reflex arc. In: De Jong W, Provoost AP, Shapiro AP (Editors), Hypertension and Brain Mechanisms. Amsterdam: Elsevier; 1977. p 9-34.

14. Saper CB, Reis DJ, Joh T. Medullary catecholamine inputs to the anteroventral third ventricular cardiovascular regulatory region in the rat. Neurosci Lett 1983; 42: 285-291.

15. Ricardo JA, Koh ET. Anatomical evidence of direct projections from the nucleus of the solitary tract to the hypothalamus, amygdala, and other forebrain structures in the rat. Brain Res 1978; 153: 1-26.

16. Herbert H, Moga MM, Saper CB. Connections of the parabrachial nucleus with the nucleus of the solitary tract and the medullary reticular formation in the rat. J Comp Neurol 1990; 293: 540-580.

17. van der Kooy D, Koda LY. Organization of the projections of a circumventricular organ: the area postrema in the rat. J Comp Neurol 1983; 219: 328-338.

18. Talman WT, Perrone MH, Reis DJ. Evidence for L-glutamate as the neurotransmitter of baroreceptor afferent nerve fibers. Science 1980; 209: 813-815.

19. Colombari E, Sato MA, Cravo SL, Bergamaschi CT, Campos RR Jr, Lopes OU. Role of the medulla oblongata in hypertension. Hypertension 2001; 38: 549-554.

20. Machado $\mathrm{BH}$. Neurotransmission of the cardiovascular reflexes in the nucleus tractus solitarii of awake rats. Ann N Y Acad Sci 2001; 940: 179-196.

21. Schreihofer AM, Stricker EM, Sved AF. Nucleus of the solitary tract lesions enhance drinking, but not vasopressin release, induced by angiotensin. Am J Physiol Regul Integr Comp Physiol 2000; 279: R239-R247.

22. Thunhorst RL, Johnson AK. Effects of arterial pressure on drinking and urinary responses to intracerebroventricular angiotensin II. Am J Physiol 1993; 264: R211-R217.

23. Thunhorst RL, Lewis SJ, Johnson AK. Effects of sinoaortic baroreceptor denervation on depletion-induced salt appetite. Am J Physiol 1994; 267: R1043-R1049.

24. Evered MD. Investigating the role of angiotensin II in thirst: interactions between arterial pressure and the control of drinking. Can $J$ Physiol Pharmacol 1992; 70: 791-797.

25. Kaufman S. Role of right atrial receptors in the control of drinking in the rat. J Physiol 1984; 349: 389-396.

26. Thunhorst RL, Johnson AK. Renin-angiotensin, arterial blood pressure, and salt appetite in rats. Am J Physiol 1994; 266: R458-R465.

27. Colombari E, Menani JV, Talman WT. Commissural NTS contributes to pressor responses to glutamate injected into the medial NTS of awake rats. Am J Physiol 1996; 270: R1220-R1225.

28. Menani JV, Colombari E, Talman WT, Johnson AK. Commissural nucleus of the solitary tract lesions reduce food intake and body weight gain in rats. Brain Res 1996; 740: 102-108.

29. Schreihofer AM, Anderson BK, Schiltz JC, Xu L, Sved AF, Stricker EM. Thirst and salt appetite elicited by hypovolemia in rats with chronic lesions of the nucleus of the solitary tract. Am J Physiol 1999; 276: R251-R258.

30. Thoren P. Reflex effects of left ventricular mechanoreceptors with afferent fibers in the vagal nerves. In: Hainsworth R, Kidd C, Linden RJ (Editors), Cardiac Receptors. Cambridge: Cambridge University Press; 1976. p 259-277.

31. Edwards GL, Beltz TG, Power JD, Johnson AK. Rapid-onset "needfree" sodium appetite after lesions of the dorsomedial medulla. Am J Physiol 1993; 264: R1242-R1247.

32. Fitzsimons JT, Stricker EM. Sodium appetite and the renin-angiotensin system. Nat New Biol 1971; 231: 58-60.

33. Thunhorst RL, Morris M, Johnson AK. Endocrine changes associated with a rapidly developing sodium appetite in rats. Am J Physiol 1994; 267: R1168-R1173. 